\title{
Publisher Correction: Psychopathy
}

Stephane A. De Brito (D), Adelle E. Forth, Arielle R. Baskin-Sommers, Inti A. Brazil, Eva R. Kimonis, Dustin Pardini, Paul J. Frick, Robert James R. Blair and Essi Viding

Correction to: Nature Reviews Disease Primers https://doi.org/10.1038/s41572-021-00282-1, published online 08 July 2021.

In the original version of this Primer, S.A.D.B. was incorrectly omitted from the Mechanisms/pathophysiology part of the Author contributions statement. This has been corrected in the HTML and PDF versions of the manuscript.

https://doi.org/10.1038/s41572-021-00294-x | Published online: 20 July 2021

(c) Springer Nature Limited 2021 